\title{
BIODIVERSITY CONSERVATION AND AGRICULTURAL TERRACES: A CASE STUDY ON THE ISLAND OF KYTHIRA (GREECE)
}

\author{
Alexandra Solomou ${ }^{1}$
}

DOI: https://doi.org/10.31410/ITEMA.2019.13

\begin{abstract}
Agricultural terraces and terrace walls are a conspicuous feature of the Mediterranean landscapes. The aim of the study is the contribution of agricultural terraces and terrace walls in the biodiversity conservation of the Kythira island. Analysis of the literature from the main academic resources databases and personal interview surveys indicate that agricultural terraces and terrace walls provide various goods and services, which are vital, and they are potential and interesting resources for the development of this area. It is noteworthy that agricultural terraces and terrace walls are an important habitat for biodiversity. Consequently, these landscape elements should be preserved and exploited as favor the components of biodiversity which are the source of our food and medicines, fibers, fuels and industrial products. The direct uses of the components of biodiversity contribute substantially to the economy and tourism development.
\end{abstract}

Keywords: Flora, Fauna, Environment, Protection, Agrotourism, Mediterranean.

\section{INTRODUCTION}

\subsection{The Natural Environment of Kythira}

$\mathrm{T}_{\mathrm{r}}^{\mathrm{h}}$ he island of Kythira, also known as Cerigo, is located south of the southeastern tip of the Peloponnese. The area of Kythira is $277.28 \mathrm{~km}^{2}$ and the length of the coastline is 114.24 $\mathrm{km}$, while taking into account the 22 islands around it, the total area is $278.65 \mathrm{~km}^{2}$. Its general geomorphologic picture is semi-mountainous, dominated by a low plateau of 200-300 meters, which is often interrupted by gorges and some valley-like configurations. This plateau leads to steep cliffs to the west and south, and to the east and north, to smoother and lower formations, with many beaches. There are several islands and islets around, with the most important being Dragonares in the east and Avgo or Hitra in the south (Aggelidis et al., 2016). Most of the Kythira area belongs to the category ,forests and semi-natural areas” $(63.35 \%), 36.38 \%$ of the total area belongs to the category ,agricultural areas” and $0.27 \%$ to artificial areas (Figure 1).

The climate of Kythira is temperate Mediterranean. According to Hellenic National Meteorological Service (HNMS) statistics (1955-1997), the region is characterized by a dry, warm season during the summer months, with relatively high temperatures and moderately low temperatures during the winter months. It is noteworthy that Kythira possesses significant natural wealth (flora and fauna), composing a highly versatile mosaic that can offer multiple emotions to the visitor.

Specifically, the EZD area GR3000010 - NISIDES KYTHIRON: PRASONISI, DRAGONERA, ANTIDRAGONERA (total area: $989.13 \mathrm{ha}$ ) is important for flora [e.g. Allium gomphrenoides Boiss. \& Heldr., Anthemis scopulorum Rech. f., Centaurea raphanina subsp. mixta

Institute of Mediterranean and Forest Ecosystems, Hellenic Agricultural Organization "Demeter", N. Chlorou 1, 11528, Ilisia, Athens, Greece 
(DC.) Runemark etc.], the bird (eg Anthus campestris, Falco eleonorae, Lanius senator etc.) and its mammals (eg Monachus monachus, etc.). Also, SPA GR3000013 - KYTHIRA KAI GYRO NISIDES: PRASONISI, DRAGONERA, ANTIDRAGONERA, AVGO, KAPELLO, KOUFO KA FIDONISI (total area: $5392.46 \mathrm{ha}$ ) (Map 1) are important for breeding species and marine species. It has been designated as SPA for the following birds: Calonectris diomedea, Puffinus yelkouan, Phalacrocorax aristotelis, Falco eleonorae, Falco peregrinus, Larus audouinii and Emberiza caesia (FILOTIS, 2018).

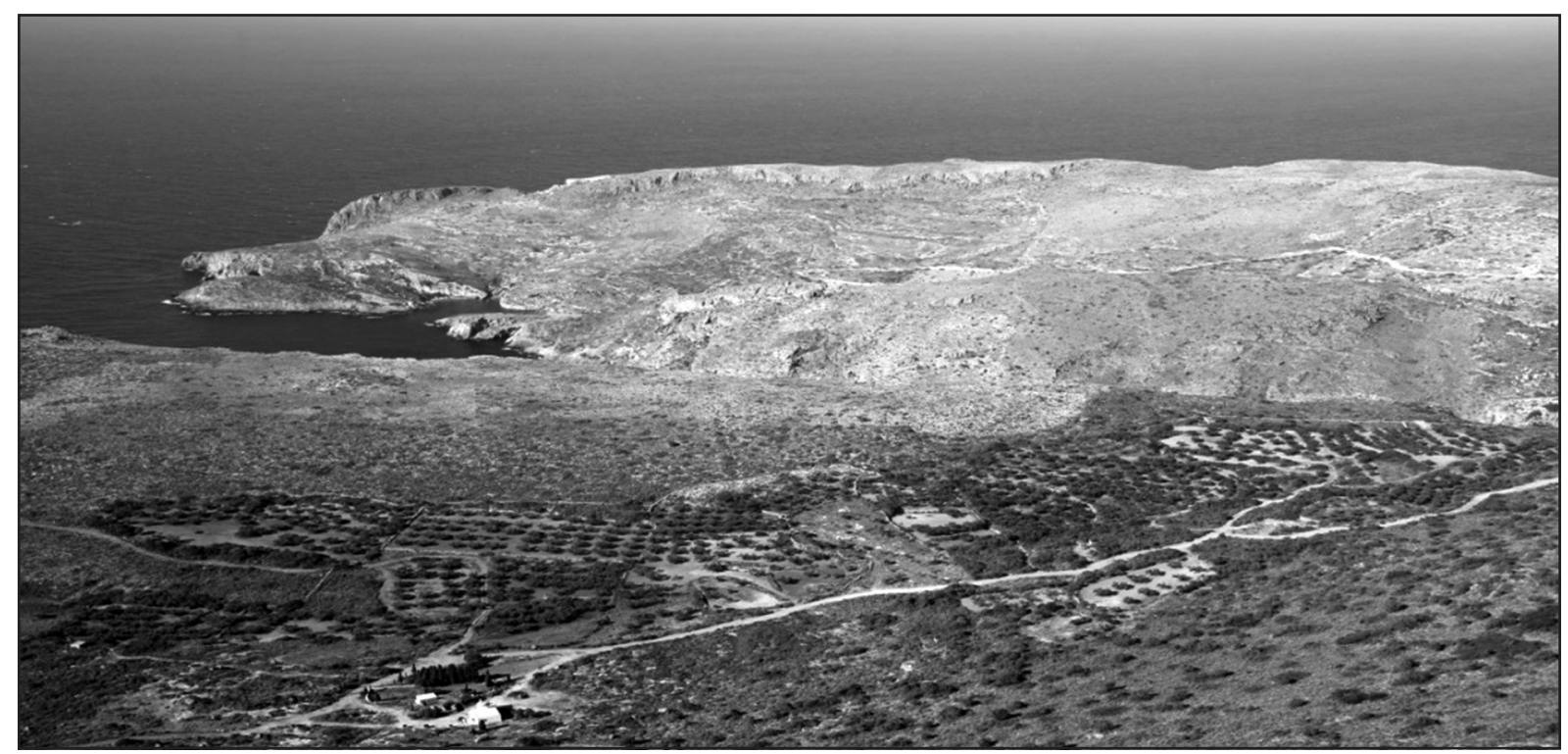

Figure 1. The Natural Environment of Kythira (Photo: Dr Alexandra Solomou).

\section{MATERIALS AND METHODS}

Data for the current study were taken from previously published work and to ensure the credibility only indexed research and review articles were used. The databases were included: Scopus, Google Scholar, PubMed, Science Direct, and MEDLINE. Also, we carried out personal interview surveys (Fowler, 2002) with the residents of Kythira island (Map 1) in 2017 and 2018.

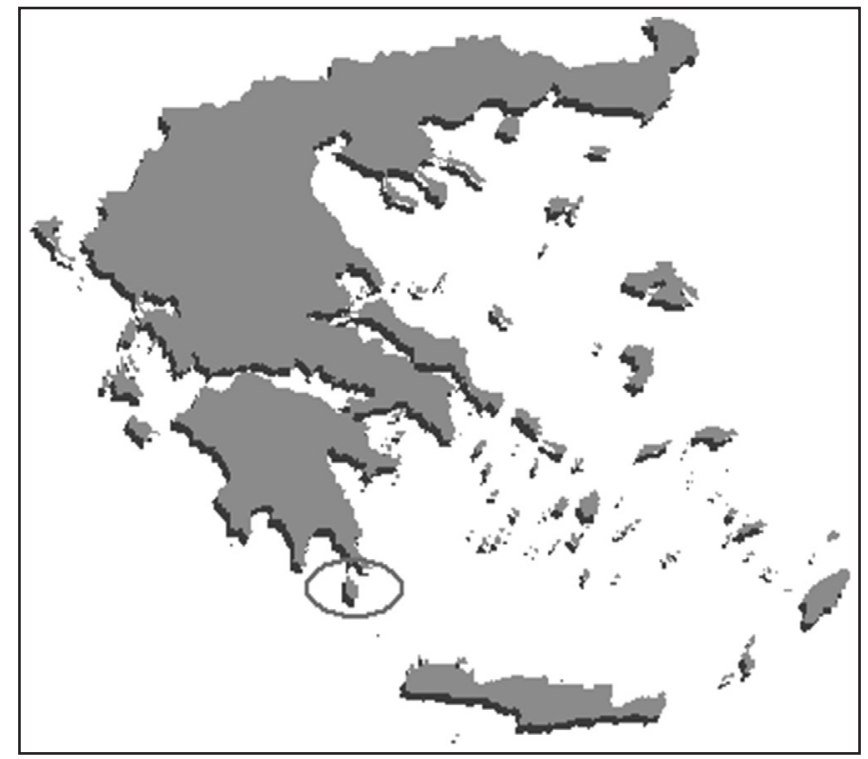

Map 1. Greek island Kythira. 


\section{RESULTS AND DISCUSSION}

\subsection{Dynamics of stone terraces and walls in the natural environment}

The island of Kythira is the crossroad of Mediterranean cultures. The fire caused in 2017 exposed the stone terraces and walls (Figure 2), works that span hundreds of years, whose maintenance and extension continued until the 1960s, as they are elements of the Greek landscape and its features. Greek countryside. According to Koulouri (2004) terraces are, historically, one of the most important and characteristic human interventions in shaping the Mediterranean landscape. They are a very important element of the historical and cultural heritage of the Mediterranean peoples and at the same time of great aesthetic and environmental value.

The stone terraces and stone walls (Figure 2) are very likely to have been conceived by the island's inhabitants in ancient times so that they can cultivate the land, mainly due to the steep the slope of the soil and to some extent secure their survival. Traditionally, the art of tiering has been passed down from generation to generation, among members of each artisan family. Terrestrial farming has largely been abandoned by the mechanization of agriculture, extensive farming and the reduction in the share of human labor in agricultural production (Crhysanthaki, 2005).

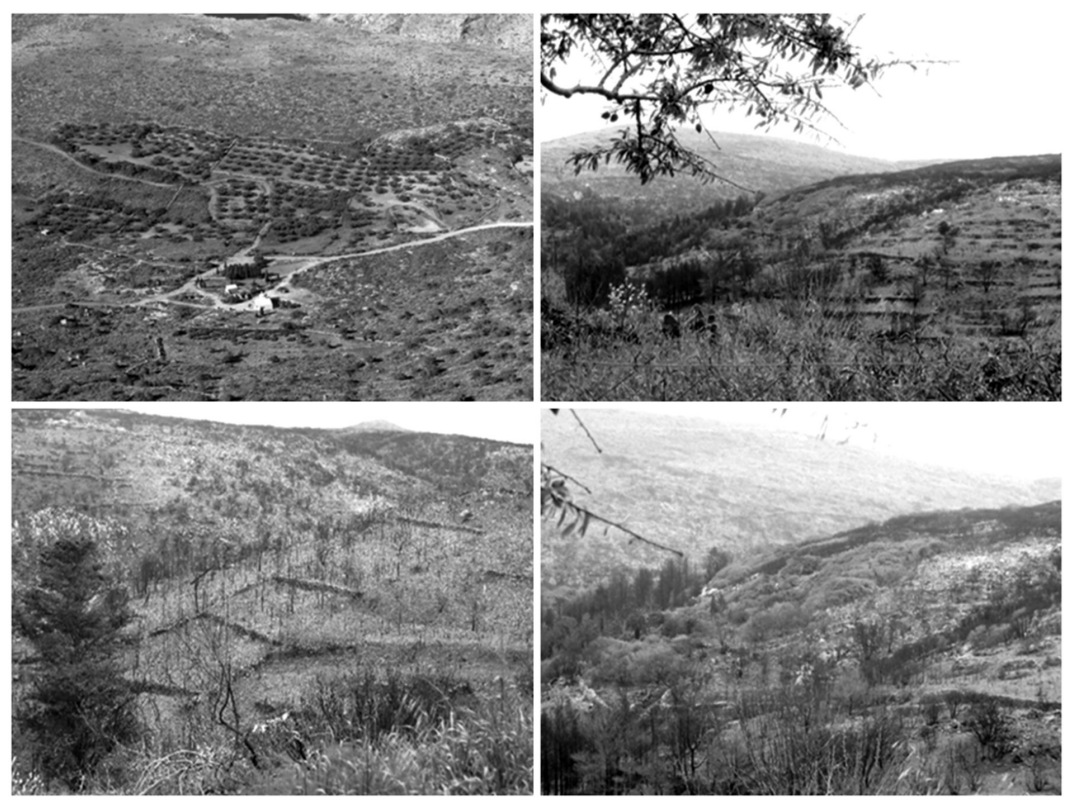

Figure 2. Stone terraces and walls in the Kythira landscape (Photo: Dr Alexandra Solomou).

It is noteworthy that the systems of stone terraces and walls (Figure 2) provide a multitude of benefits for both the environment and human societies. They provide Ecosystem Services that are vital, especially in island regions. More specifically, the most important benefits of maintaining stone terraces and walls are:

- Prevention of soil erosion, both by the action of water and by air,

- Protection during extreme weather, preventing floods and contributing to the creation of a local microclimate,

- Production, under conditions, of high-quality products,

- The creation of suitable micro-habitats for the conservation, protection and enhancement of biodiversity,

- Maintaining the high aesthetic and cultural value of the Mediterranean landscape [1,5]. 


\subsection{Contribution of stone terraces and walls to biodiversity conservation}

Stone terraces and walls are an integral part of the Mediterranean landscape (Figure 3). In many cases, they create ecological seals/habitats/nests offering a permanent or temporary refuge to various biodiversity components, e.g. invertebrates, reptiles, birds, etc. One of the reasons that terraces create fires is that they are normally oriented so that ,retaining walls during the day store solar energy, which is released at night, thereby creating local microclimate" suitable for supporting many organisms, leading thus increasing biodiversity (Vernikos et al., 2001). In essence, they create an artificial habitat and organism shelter that is enhanced by the increase in landscape mosaics.

The micro-environment at the base of stone terraces and walls is a refuge of high humidity and increased primary productivity (dense vegetation), factors which are important for invertebrate populations (e.g. spiders, phalanx, Carabidae, Staphylinida, etc.) (Arnett et al., 2002, Dajoz 2002). During the summer months the slits and openings of the stone terraces and walls accommodate large numbers of other invertebrates (e.g. snails) that pass the grouping period in a protected microclimate. This is probably due both to the high humidity of the stone terraces and walls, and to the increased calcium requirements for the construction of snail shells, factors that make them ideal environments for organisms.
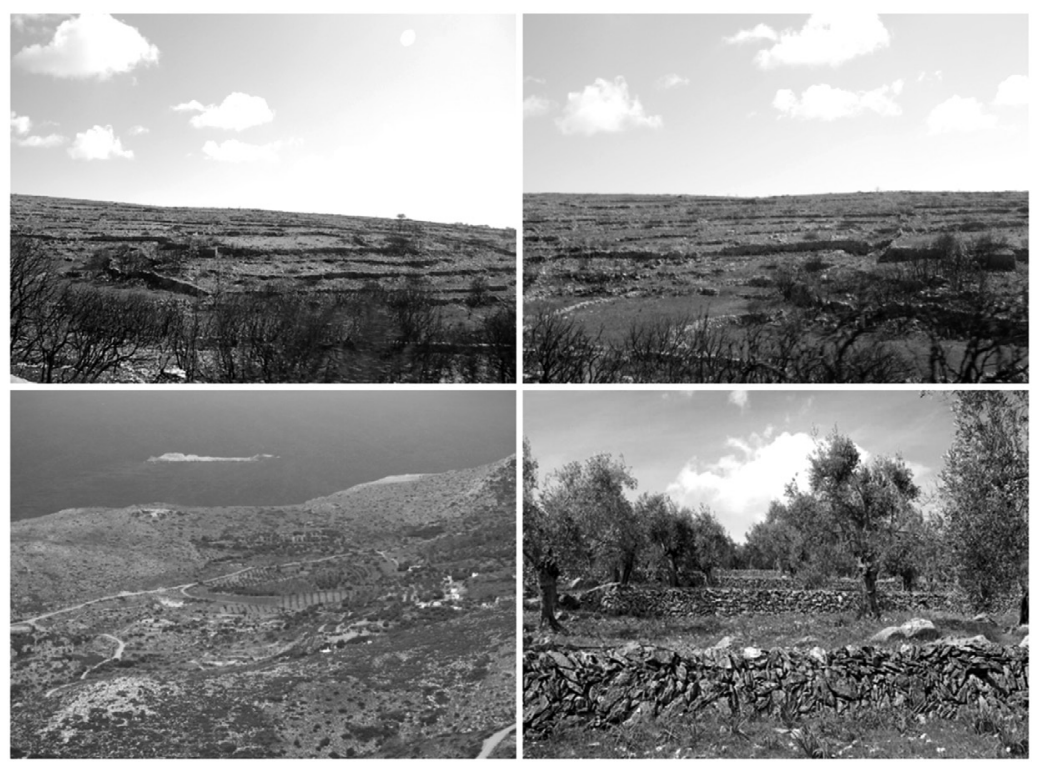

Figure 3. Stone terraces and walls as an important source of biodiversity (Photo: Dr Alexandra Solomou).

As regards the reptiles, their exothermic role plays a decisive role in the selection of ,good" calorie sites where there are rich food and predator protection (Adolph, 1990). Stone terraces and walls are places for this activity and they are selected by reptiles. In addition, these areas of the island's rural landscape are very important for wildlife, because they are an important refuge for a large number of species (e.g. reptiles, smallpox and insects) that constitute important food for many bird species.

Stone terraces and walls are also an important habitat for flora diversity and habitat for dry or shady plants as they find a safe retreat site, a haven of life. The flora that grows in these areas hosts species that are scattered by the natural flora of neighboring areas. Plant species vary greatly from place to place depending on geographical location (climate, altitude, etc.) (Peta- 
nidou, 2001). Also, the age of the building, the conservation of moisture at least once a year, and the north orientation or shading (which indirectly regulate the amount and / or moisture duration) favor the growth of herbaceous plants (Pafilis, 2014).

\section{FUTURE RESEARCH DIRECTIONS}

Future research should continue for biodiversity monitoring and management actions which will allow this wealth to maintain and to be inherited undisturbed in future generations. Also, it will be studied the promotion of agrotourism in Kythira island. It is important to be referred that agrotourism is a mild alternative form of sustainable tourism development and multiactivity in a rural area, which aims to: a) help the visitor get acquainted with the rural area, the cultural and authentic features of the area, the farming activities, the local products, the traditional cuisine and the daily life of the residents, b) bring the visitor in touch with nature as well as the activities in the countryside, in which he can participate, entertain and feel his joy navigation, knowledge, information and discovery, c) mobilize the productive, cultural and developmental forces of the place, thus contributing to the sustainable economic and social development of Kythira rural area.

In addition to the proposed framework, some additional proposals to support Kythira's development include: a) Protecting the local product and developing an integrated marketing strategy to achieve benefits at the individual and collective level and b) Strengthening the sustainable character of tourism development on the Kythira island and turning to alternative forms of tourism, in the context of exploiting the local product. This strategy would have as a result the extension of the tourist season, with even more positive consequences for Kythira island.

\section{CONCLUSION}

In conclusion, stone terraces and walls are part of the island's cultural tradition and heritage, which should be preserved and exploited with a view to an environmentally sustainable spatial development with effective and coherent protection of the environment and its cultural heritage, of biodiversity and adaptation to climate change. Finally, Greece offered to develop agrotourism because of its natural beauty and its history and tradition. The research on biodiversity, sustainability and agrotourism may provide guidance for researchers, policymakers and funding agencies to prioritize research questions and frame their activities.

\section{ACKNOWLEDGMENT}

We thank the Institute of Mediterranean and Forest Ecosystems, Hellenic Agricultural Organization "Demeter" for their bibliographic database and assistance.

\section{REFERENCES}

Adolph, S.C. (1990). Influence of behavioral thermoregulation on microhabitat use by two Sceleporus lizards. Ecology, 71(1):315-327.

Aggelidis, Ch., Georgiadis, N., Kordopatis, P., Portolou, D. and Tsiopelas, N. (2016). Recording and Evaluation of the Kythira and Antikythera Natural Environment. Mediterranean Institute for Nature and Man - Hellenic Ornithological Society, Athens (in Greek).

Arnett, R.Jr, Thomas M.C., Skelley, P.E., Frank, J.H. (2002). American Beetles, Volume II: Polyphaga: Scarabaeoidea through Curculionoidea. CRC Press LLC, Boca Raton, FL. 
Chrysanthaki, Ch. (2005). Aesthetic Value of the Upgraded Landscape and its Development in the Sustainable Development Education. Bachelor's thesis. School of Humanities. Department of Preschool Education and Educational Design Sciences. University of the Aegean. Mytilene.

Dajoz, R. (2002). Les coléoptères carabidés et ténébrionidésmTec \& Doc Lavoisier.

FILOTIS. (2018). Available at: https://filotis.itia.ntua.gr/biotopes/c/GR3000010/ (Accessed 10.10.2018).

Fowler, F.J. (2002). Survey Research Methods, 3rd ed. Thousand Oaks, CA: Sage.

Hellenic National Meteorological Service (HNMS) (1955-1997). Available at: http://www.hnms. gr/emy/el/ (Accessed 19.10.2018).

https://esajournals.onlinelibrary.wiley.com/doi/pdf/10.2307/1940271\#accessDenialLayout

Királ'ová, A., \& Hamarneh, I. (2018). Urban tourism competitiveness of selected European cities. In V. Bevanda (Ed.), Recent Advances in Information Technology, Tourism, Economics, Management and Agriculture. Paper presented at $2^{\text {nd }}$ International Scientific Conference ITEMA 2018, Graz University of Technology, Graz, November 8, 2018 (pp. 125-133). Belgrade: Association of Economists and Managers of the Balkans. https://doi.org/10.31410/ itema.2018.125

Koulouri, M. (2004). Soil water erosion and land use change in the Mediterranean: abandoning traditional extensive cultivation. Doctoral thesis. Environment Department. University of the Aegean. Mytilene.

Pafilis, P. (2014) Dry stone, biodiversity supports. Scientific Research Program 2013. Ioannis S. Latsis Public Benefit Foundation. National and Kapodistrian University of Athens, Greece.

Petanidou, Th. (2001). The role of terraces in the past and their importance for the future of the islands in terms of economy, ecology and culture. Final Technical Report to the Ministry of the Aegean. Mytilene, Greece.

Vernikos, N., Daskalopoulou, S., Paylogeorgatos, G. (2001). Proposal for Classification of Stone Structures. In M. Varte-Matarangas, Katselis Y. (Ed.), The Building Stone in Monuments. Paper presented at the International InterdisciplinaryWorkshop Scientific Conference ICOMOS - IGME 2001 (pp. 170-270) Mytilene, Greece. 